\title{
Effect of selected nursing interventions in the reduction of after-pains and involution of uterus among post-natal mothers in selected hospitals.
}

\author{
Monalisa $\mathrm{M}^{1 *}$, Pravati $\mathrm{T}^{2}$, Pratibha $\mathrm{K}^{3}$
}

\section{*Corresponding author:}

${ }^{1}$ Ms. Monalisa Mall, M.sc Nursing, Msc Tutor, Department of Obstetrics and Gynecological Nursing, SITE- A school and college of Nursing, Balangir, Odisha, India

Email: monalisamall85@gmail.com ORCID

${ }^{2,3}$ Department of Obstetrics and Gynecological Nursing, SUM Nursing college, Bhubaneswar, Odisha, India

Information about the article:

Received: Jan. 17, 2019

Accepted: Feb. 20, 2019

Published online: Dec. 27, 2019

\section{Publisher}

Nepal Health Research Society, Bahundhara -6, Gokarnesowor Municipality, Kathmandu, Nepal eISSN 2382-5545, ISSN 2676-1343 (Print)

(c) The Author(s). 2019

Content licensing: CC BY 4.0

\begin{abstract}
Background

The wonder of motherhood is the enjoyable journey that is felt only by the mother after giving birth. During postnatal period, the mother experiences problems like afterpain, back pain, pain in leg, breast engorgement, perineal discomfort, fatigue etc.
\end{abstract}

\section{Material and methods}

This study focus on finding the effect of selected nursing interventions such as ambulation, emptying bladder, deep breathing exercise, fundal massage, alternate leg raising and Kegel's exercise in reducing afterpain and improving involution of uterus among postnatal mother in selected hospitals of Bhubaneswar by quantitative experimental research approach of Quasi experimental non randomized control group design. Purposive sampling technique was used to select the 60 postnatal mothers. Data were collected through Self-structured Questionnaire on socio- demographic, standardized numeric pain intensity scale on after pain and Self-structured rating scale on assessing involution of uterus. Descriptive and inferential statistics were used for analyzed the collected data.

\section{Results}

The study findings revealed that $83.3 \%$ of postnatal mothers had no pain and $96.7 \%$ had fundal height bellow umbilicus. After pain level in experimental group with the 't' value was 20.79 at p value 0.05 level, which is statistically significant. There was significant difference observed between pre and post test mean score of after pain level and involution of uterus at $\mathrm{p}<0.0001$. There was notable association between parity of mother and afterpain level at $\chi 2=10.44$.

Conclusion: It conclude that rendering of planned nursing interventions to the postnatal mothers were helpful in dropping the level of after pains and improves in involution of uterus. Therefore, the investigator felt that more importance should be given to assess the post partum afterpain and involution of uterus experienced by the mother and measures should be taken seriously in order to reduce the afterpain and improves involution of uterus.

\section{Key words}

Afterpain, involution of uterus, nursing intervention. 